\title{
Planetary health in practice: sensing air pollution and transforming urban environments
}

Jennifer Gabrys (iD ${ }^{1 凶}$

Often, health is seen to be a matter of attending to individuals and their behaviour, or of studying populations in order to manage disease. However, pollution is a problem of the health of environments, as much as it is a problem of the health of bodies. To understand health and pollution, it is necessary to examine energy-intensive infrastructures and developed environments that produce air pollutants and impair ecosystems. In other words, air pollution requires approaches to health that are planetary in scope and that account for the socio-environmental processes and relations that make health possible. Planetary health is often approached as a broad analysis of earth systems. However, diverse and situated environmental practices also contribute to the formation of planetary health. This article asks how citizen-sensing practices tune into the problem of air pollution in Southeast London, and in so doing differently configure pollution and planetary health. While many sensing technologies promise to make citizens into more capable political actors through the collection of data, this research investigates how communities use sensors in distinct ways to support, activate or extend community-led projects in urban environments. Rather than citizensensing practices contributing to improved air quality through the abstract circulation of data, we found that environmental monitoring became enmeshed in ongoing and broader struggles to improve the health of urban environments. These practices not only challenge the official scripts of sensing devices, they also remake the usual ways of demarcating health in relation to air pollution by shifting away from individual behaviour and toward collective environmental actions. This article then asks how community proposals for urban design and action conjoin with citizen-sensing practices to generate strategies for reworking and reconstituting health toward more planetary compositions.

\footnotetext{
${ }^{1}$ Department of Sociology, University of Cambridge, Cambridge, UK. ${ }_{\text {email: jg899@cam.ac.uk }}$
} 


\section{Introduction}

he air is teeming with pollutants. Particulate matter and nitrogen oxides, ozone and sulfur dioxide drift and accumulate near and far from emission sources. Worldwide, between 7 and 8.8 million people die from air pollution related causes every year, with $\sim 4.2$ million people dying due to outdoor (or ambient) air pollution. ${ }^{1}$ The majority of these fatalities occur in India and China, where industry, traffic, and agricultural practices often contribute to lethal levels of ambient pollution. Other countries in Africa and Asia where cooking indoors with open fires is a common practice also have a high incidence of deaths related to indoor air pollution. At the same time, deaths related to air pollution in Europe are now thought to be underestimated, with $\sim 800,000$ people dying annually from air pollution-related causes (Lelieveld et al., 2019). As Das and Horton (2017, p. 407) note, "no country is unaffected by pollution" (see also Landrigan et al., 2018). In multiple locations, air pollution has become evident as a planetary problem through a pervasive but differential array of health effects.

Often, health is seen to be a matter of attending to individual lifestyles and behaviour, or of managing populations in order to manage disease. While the effects of air pollution on the human body continue to be a topic of extensive research and study-with every part of the body now understood to be affected by air pollution (Loxham et al., 2019) - this damage cannot be contained at the scale of the individual or population. To understand health and pollution, it is necessary to examine energy-intensive infrastructures and developed environments that produce air pollutants and impair ecosystems. Indeed, reductions in ambient air pollution through environmental interventions can contribute to almost immediate observable improvements in health (Schraufnagel et al., 2019). Pollution is a problem of the health of environments, as much as it is a problem of the health of bodies. Air pollution thus requires approaches to health that are planetary in scope in order to account for the socio-environmental processes and relations that make health possible. Yet the planetary here is less a matter of a whole-earth system, and more a problem of the variegated and differential ways in which air pollution affects environments and health.

Planetary health is an emerging area of study that seeks to understand how possibilities for health are intricately connected to the health of the planet (Ekins et al., 2019). Often manifesting as a broad analysis of earth systems (Haines et al., 2018), the field of planetary health recognizes air pollution to be among the most severe forms of damage to planetary systems, along with climate change and biodiversity loss. However, diverse and situated environmental practices contribute to the formation of planetary health. These practices typically operate less as an overview of systems and more through diverse environmental engagements. This article investigates how citizen-sensing practices tune in to the problem of air pollution in Southeast London, and in so doing reconfigure the planetary and planetary health as a proposition to move beyond total earth systems to work with differential conditions of environmental injustice.

In the process of discussing and analysing citizen-led air quality monitoring, this article poses three questions to study how citizen-sensing practices compose, propose and reconfigure health as a planetary formation. First, I ask how do citizens and communities document, monitor and act upon air pollution as a problem of the health of environments? Second, by questioning the designation of the "planetary" as a potentially universal rendering of environments and subjects, I ask how a more differential and situated approach to the planetary could allow for greater attention to health practices and politics that emerge especially through attempts to shape environments? Third, by attending to the diverse social, political, material and environmental processes whereby planetary health is composed, I ask how do citizens and communities work toward potentially more democratic and expansive possibilities for constituting planetary health as a project of forming and transforming environments and collectives? These questions depart from approaches that begin with individual affected bodies and harm already incurred, or from perspectives of a total earth system, to instead consider how environmental actions constitute and reconstitute health toward planetary compositions that query and compose the planetary through the very practices that would observe and mitigate pollution.

I address these questions by drawing on science and technology studies, environmental justice and postcolonial theory, and planetary health literature to first establish how citizen monitoring of pollution potentially contributes to the democratization not only of environmental evidence but also of environmental action. Within this context, I analyse how citizen sensing reworks practices of environmental observation, while differently constituting health and pollution. I specifically consider how environmental interventions become a key aspect of how health is composed toward affiliations that might be described as planetary, but not in the usual sense of "planetary scale". I then describe in more detail how the Citizen Sense research project collaborated with local communities in Southeast London to set up a citizen-sensing network. This research analyses how communities sought to identify and document poor air quality, and to collect and communicate evidence of pollution episodes and hotspots in their neighbourhoods. People did not collect data merely to demonstrate whether air pollution levels were high, however, but instead mobilized their environmental observations along with and in support of ongoing community proposals and actions to address air pollution. I focus on three of these actions, including sustainable transport, green infrastructure, and citizen participation in air quality monitoring, to examine how distinct formations of health materialize through attention to air pollution.

While many sensing technologies promise to make citizens into more capable political actors through the collection of data, this research investigates how communities use sensors in much different ways to support, activate or extend community-led projects that engage with urban environments. Rather than citizen-sensing practices contributing to improved air quality through the abstract circulation of data, we found that environmental monitoring became enmeshed in ongoing and broader struggles to improve the health of urban environments. These practices not only challenge the official scripts of sensing devices, they also remake the usual ways of demarcating health in relation to air pollution. In this way, they shift away from changing individual behaviour or raising awareness and move toward collective actions that intervene within the environmental conditions that make health possible. In this sense, monitoring was neither a process of making the problem of air pollution simply "visible," nor were urban interventions the direct outcome of sensing. Instead, sensing practices became enrolled in ongoing projects and contributed to the co-constitution, facilitation and even complication of strategies for addressing air pollution as a problem of urban environments and planetary health.

By investigating how communities undertake environmental interventions to address air pollution, this article seeks both to establish how citizen sensing folds into ongoing practices to remake the city, and how these practices generate alternative approaches to planetary health. Citizen-led practices of sensing environments and forming evidence, I suggest, do not simply document how individual bodies in specific locations are affected by air quality. Moreover, monitoring practices are not only 
evidentiary or documentary techniques. Instead, these practices compile into more collective and infrastructural observations and proposals for how to compose environments as expressions of planetary health. The planetary, as I will discuss below, operates as a figure of collective responsibility and environmental relation, as much as an indicator of global systems. In a similar way, as Hinchliffe et al. (2018) have suggested, "health has become a collective project" that brings "together people, nonhuman animals and ecologies" as well as "planetary processes" (Hinchliffe et al., 2018). Such a collective project is not only one of engaging democratic actors to transform approaches to health (cf. Felt and Fochler, 2010), but also one that distinctively activates the social, political, material and environmental subjects, processes and relations that constitute health. The planetary, in other words, is less a settled unit of analysis and more a collective composition in the making. It is these processes of directly and indirectly configuring, reworking and experimenting with health as a collective and planetary proposition that this article investigates from the perspective of one participatory air-quality-monitoring study in London.

\section{From environmental observations to environmental interventions}

Citizen monitoring of air quality is now a common practice of environmental engagement. Through the use of buckets and badges, diffusion tubes and dust wipes, citizens can capture air and particle samples that are typically sent to laboratories for analysis. These practices have often involved analogue techniques for environmental monitoring and observation (Corburn, 2005; Ottinger, 2010), yet over the past 15-20 years digital sensor-based techniques have been in development. While low-cost digital sensors were somewhat unreliable when first developed, they are now increasingly accessible and accurate. These digital techniques and sensors can create networked, spatially dense and real-time monitoring networks that generate distinct approaches to environments, health and participation (Gabrys, 2019b; Chatzidiakou et al., 2019; English et al., 2018).

While there are now multiple digital citizen-sensing projects underway, from environmental justice projects in the Imperial Valley in California to citizen-monitoring projects in Paris and Munich, there are still many uncertainties about how or whether these technologies facilitate alternative or more effective approaches to pollution. Sensors initially seem to organize air pollution as a problem of data collection, which is meant to lead to more effective mitigating actions through informational modes of governance. Although technology companies focus on producing enticing gadgets and collecting copious amounts of data, ${ }^{2}$ the actual ways in which citizen practices for monitoring air quality are undertaken is less well studied or understood. It is within this context that the Citizen Sense project began its research in 2013, when it set out to investigate how digital citizensensing technologies were being taken up by diverse actors to monitor environments. Through practice-based and participatory techniques, our research group has investigated how these sensing devices influence citizen participation, as well as whether they fulfil their intended functions or if they give rise to unexpected practices of environmental engagement (cf. Michael, 2009). The Citizen Sense project has researched how sensors are put to use, but it does so through testing, building, and installing sensors with communities concerned about air quality. At the same time, the research project critically engages with the possibilities and limitations of these devices, rather than necessarily advocating for their use. In this way, this research into how sensors operate and the forms of community monitoring that they facilitate does not develop through more distanced study "on the other" (Tuck et al., 2013, p. 53; cf. Smith, 1999), but instead takes place through direct engagement and collaboration with people, environments, and technologies as they inform and complicate attempts to address air pollution.

Citizen-sensing practices can be situated within a wider array of projects that engage with citizen observations and evidencemaking. Citizen-led experiencing, witnessing and attesting to the health of environments and bodies are practices that can potentially contribute to democratic participation through a "popular equality of perception" (Chilvers and Kearnes, 2016, p. 3). However, such equality of perception is often much more difficult to realize in practice since on the one hand it could require gaining access to and mobilizing the techniques and instruments -or "sensory organs"-of science (Beck, 1993, p. 27), while on the other hand it could be rendered "anecdotal" if composed of everyday experiences. In this way, environmental justice research has documented how peoples' experiences with pollution-related illnesses do not always correspond to scientific studies or data that attempt to corroborate their claims. Citizens who gather their own data to document pollution, illness and environmental harm are often suspected of bias, and their evidence is disregarded. As Corburn (2005) documents, people living near the World Trade Center after 9/11 experienced multiple health effects that they suspected to be from air pollutants. When they were told that expert monitoring from the US Environmental Protection Agency (EPA) did not produce evidence that could verify their claims, they found that they needed to query and challenge expert opinion and practice in order to have their concerns taken seriously. Pollution, as well as the conditions for documenting harm to health, became differently experienced, monitored and understood in these institutional and citizen practices.

Remaking health to remake environments. A more democratic approach to the experience and perception of environmental pollution and harm is not only a way to challenge expert opinion and account for a broader array of lived environmental experiences, however. It could also generate more expansive practices of configuring and acting upon pollution and health (Bickerstaff and Walker, 2003; cf. Benjamin, 2013; Epstein, 1995; Fortun et al., 2014; Garnett et al., 2019; Yearley, 2011). An expert-driven approach to monitoring pollutants might be based on regulatory objectives and laboratory conditions for monitoring pollutants. But a citizen and community approach to assessing pollution might attend to actual lived conditions of multiple forms of pollution accumulating over time, as well as possibilities for preventing pollution (Gabrys, 2017). As Corburn suggests, "community-generated information can, in fact, be used to improve environmental health decision-making" (2005, p. 3). Perception in this sense can become more or less "equal" because of access to scientific instruments and infrastructures, and because observations and evidence are diversely mobilized to document pollution and to organize actions that would address and mitigate this problem. However, rather than put forward policies or reports that indicate when air pollution thresholds are not met, communities are more likely to suggest environmental interventions in the form of green spaces, traffic restrictions, and protests against construction. The apparent democratization of environmental evidence then draws attention to how proposals for environmental action might also be democratized.

The democratization of community monitoring, experience and perception, can give rise to an expanded array of data that differently captures pollution, while provoking collective action to transform environments in order to transform the conditions of health. Community monitoring of air pollution is a mode of inquiry that uniquely constitutes the health and pollution of environments. By collecting air pollution data, citizens are already 
exceeding the usual regulatory and expert-driven practices for air quality monitoring, which are established to comply with air quality objectives, while also drawing on these datasets and reports. These regulatory standards and objectives are formed through epidemiological datasets, statistical averages, and population trends, as well as expert monitoring practices that attend to particular formations of health (European Commission, 2008; World Health Organization, 2005). However, community monitoring engages expert datasets along with health and pollution as understood through citizen monitoring, lived experiences, environmental inhabitations, bodily responses, and social and political relations that might need to be influenced or generated in order to act on the problem of air pollution. With these expanded modes of encounter, health and pollution materialize less as statistical targets or objectives and instead become sites of intervention for transforming environmental and social relations (cf. Kelly et al., 2017).

In a related way, Nelson (2011) has suggested that definitions of what counts as "health" are not self-evident, and require ongoing negotiation with, and participation by, people. Writing in the context of health advocacy and radical health experiments undertaken by the Black Panther Party in the 1960s and 1970s, she demonstrates how "health is politics by other means". ${ }^{3}$ She documents how health was a site of exclusion, in part because the very definitions of health created injustices within the practices of healthcare. Such restrictions to health were challenged through DIY and community health projects undertaken by the Black Panther Party, which were not simply projects for extending institutional health practices to marginalized people. Even more, through creating particular communities, sites, practices and relations, they remake the very conditions and possibilities of health. This is part of what forms the "polyvalence" of health, as Nelson terms it, which through its redefinition and transformation can become "a powerful and elastic political lexicon" to capture ideals, address injustice, and work toward equality (2011, p. 5). Health in this sense becomes a transformational project, which political subjects, communities and practices configure in distinct ways. It is such a transformational approach to health that I suggest citizen-sensing practices could activate in relation to planetary propositions for health.

Planetary health: configuring sites of struggle. The incorporation of the environmental and planetary conditions that enable health further pushes at the usual ways in which health is understood and practiced. In this way, planetary health is an emerging field that attends to the interrelated health of humans and natural systems (Horton and Lo, 2015; Whitmee et al., 2015). Planetary health is somewhat of a unifying concept that brings together the concerns of global health, public health and environmental health while including connections to earth systems as the basis for health, but which are in peril. The conception of the "planetary" in planetary health is largely one of identifying systems and boundaries that are at breaking points, and of proposing that new approaches are needed to address overconsumption, inequities, interconnectedness and the need for broad social action. In this search for "a new principle of planetism" (Horton et al., 2014), planetary health scholars and practitioners propose expanded forms of collective action in order to work toward sustainable human development.

While this move to planetary health is laudable, the challenges that its proponents identify-including imaginational or conceptual challenges, knowledge and information challenges, and governance challenges (Whitmee et al., 2015), may also affect the very formation of this field, since the planetary is self-evidently identified as the large-scale study of systems and boundaries; information and knowledge involves filling data gaps within a universal episteme; and governance is neatly divided into six layers that are meant to inform one another seemingly without struggle. The planetary in planetary health is then a figure that requires further unsettling and opening up, especially from the perspective of projects that would undertake democratized environmental monitoring and action in the interests of engaging with planetary health as a propositional project that is in the making, rather than predetermined.

Urgent actions, along with engagement with "grassroots" or civic organizations, are especially seen to be key components for addressing planetary health challenges (Whitmee et al., 2015). The call to engage with civic groups and join up diverse communities across science, health and governance is compelling in principle, but civic contributions to the formation of planetary health and its challenges are not readily evident in the usual ways of composing the problem of planetary health. In this way, Hinchliffe et al. have noted that while proposals to engage with civil society to address health are timely and relevant, the actual details of these participatory initiatives are significantly underspecified $(2018$, p. 4$)$. Indeed, the power dynamics that have led to health inequalities and environmental damage are not easily remedied by joining up multiple forms of political engagement and governance, and "these collectives will take serious and intense experimentation and work" (Hinchliffe et al., 2018, p. 4; cf. Pritchard and Gabrys, 2016). Part of this experimentation might begin in addressing the very way in which the planetary is composed as a unit of analysis and action.

A clear example of such friction comes in the form of citizensensing practices that would monitor and document air pollution. Here are practices that would add to the "gaps" in information relevant to the planetary health problem of air pollution, and yet, they do not operate within a universal scientific episteme to which they could readily add observations and evidence. Citizen data operates less as an over-arching view of earth systems, and even less as an integrated surveillance project (cf. Haines et al., 2018). Instead, it consists of a more situated array of efforts to mobilize evidence in support of distinct environmental actions. Information, knowledge and evidence gathered in these distinct ways and for specific purposes are then as likely to generate considerable misalignments, as they are to add up to a universal project of planetary health. The planetary in this way is not a settled figure of consensus, and instead is a more differential project of searching toward collective inhabitations.

There are then other ways in which the planetary might materialize as a vector of practice and relationality in the making (Gabrys, 2018), which might align with projects to differently configure health. While planetary health as usually framed serves a way to engage with earth systems and health (Gupta et al., 2019), the use of the planetary as an overview of large-scale processes can further replicate dynamics of coloniality and domination that have a history of political subjugation (cf. DeLoughrey, 2014). The re-imagining of the planetary, as Spivak has termed it, can become a way to re-imagine subjects, collectives and responsibility in ways that generate other possibilities for becoming planetary. The planetary is as much a figure that can unsettle and force other forms of collective responsibility, while generating distinct planetary subjects, that work from within an "inexhaustible diversity of epistemes" (Spivak, 1999, p. 74). In this way, struggles for planetary health take place not necessarily at the level of the globe-as planetaryscale phenomena-but rather through open-ended and situated environmental practices that transform relations across subjects, environments and health, while also signalling that these 
problems of pollution are differentially shared across multiple sites.

The formation of the "planetary" then has consequences for the configuration of political subjects, the modes of governance, the forms of action, and the mobilization of collectives and health that are articulated in proposals to act on air pollution or planetary health (cf. Holgate, 2017). In this more processual and differential approach to the planetary, it might be possible to tune into the ways in which the planetary erupts and is articulated through practices that attempt to transform collective inhabitations. Here, both the planetary and health are reconfigured, not as a matter of scale of individual behaviour, but rather as the desire to transform environments and everyday practices in order to address the conditions of planetary health. However, the ability for communities to configure and transform health as an environmental project comes up against environmental inequalities and power dynamics that they might have a varying ability or inability to work against or reshape. People and communities who are undertaking campaigns to address the health of urban environments find that their voices are not equally heard or responded to-and that those whose voices register are often already in positions of privilege.

While planetary health acknowledges that the problem of environmental pollution most often affects people living in lowincome to middle-income countries (Das and Horton, 2017; Whitmee et al., 2015), the geo-political and social-political dynamics of these inequalities are at times not precisely rendered across the multiple sites and countries where disparity affects health, including in higher-income countries. Planetary health forces attention to whose health benefits, and at what cost to other people and environments. It further forces attention to how actions to improve planetary health are undertaken, by whom, and in what ways. As has been similarly established through studies of environmental justice, exposure to poor environmental conditions often aligns with endemic inequalities, including racism and classism (Bullard, 1990; Pulido, 2016; Sze, 2007; Walker, 2012). Environments have developed as expressions of unhealthiness through inequality and in justice. They further reproduce and reinforce injustice through entrenched material conditions of inequality. Health in this sense is less a matter of becoming healthy through lifestyle changes or individual betterment, and more about addressing the social and political conditions that form unequal and unhealthy environments. In a similar way, the planetary in "planetary health" signals the need to address the social-political and economic practices and relations that influence how environments materialize. Keeping in mind this provocation to rethink the planetary in planetary health, along with the proposal to consider how environmental action as much as environmental observation might be democratized, I now turn to discuss in more detail three actions that arise from citizen-sensing efforts that reorient health toward more planetary compositions.

\section{Planetary health in practice}

Similar to many cities in the world, London has an ongoing problem with air pollution that leads to over 9000 deaths per year due to air pollution. Residents in the area of Deptford and New Cross were reasonably well informed about this problem, and at the same time air pollution was not the only thing that guided their wider efforts to address the urban realm. Air pollution, and its associated health effects, was from the start a problem that was integrated with wider struggles that engaged with urban environments. It was within this context that the Citizen Sense group began its research in the spring of 2016 as part of a longer 6-year project funded by the European Research Council by identifying existing community projects involved in monitoring environments. We found that groups were undertaking traffic counting in order to calm busy streets, they were setting up diffusion tubes to capture levels of nitrogen oxide pollutants, and they were using maps and related data to establish how much green space was available in the area (see also Houston et al., 2019). While many people were concerned about the health effects of pollution, whether in relation to their own health or the health of friends, family, and neighbours, they were even more oriented toward shaping and remaking urban environments as a key way in which to address the problem of urban change and health in ways that assembled as a problem of planetary health. From campaigns to save community green space to sustainable transport pilots, their practices worked toward alternative approaches to health not as harm already done to individual bodies, but as the possibility to prevent and mitigate pollution in order to construct more favourable contexts in which to live.

During this preliminary research into existing monitoring practices and related initiatives, we formed initial connections with community groups, workers and residents engaged in monitoring environments in order to establish the possibility for undertaking a collaborative study into citizen-sensing technologies. Over the summer of 2016, we attended community meetings and summer festivals, demonstrated citizen-sensing devices, and discussed the ways in which pollution monitors might be used in the area. We then brought these insights into the development of a citizen-sensing infrastructure that built on our previous experience in monitoring air pollution. We developed a low-cost DIY sensor, the Dustbox, to monitor one of the most hazardous air pollutants, particulate matter $2.5\left(\mathrm{PM}_{2.5}\right) . \mathrm{PM}_{2.5}$ is a pollutant that has been studied for decades for its adverse health effects and health-related research has demonstrated clear connections between increasing levels of $\mathrm{PM}_{2.5}$ and hospital admissions (Dockery et al., 1993). This research has gone on to inform decades of health research and guidance (Grigg, 2017; Royal College of Physicians, 2016; WHO, 2005). At the same time, particulate matter is not extensively monitored at regulatory monitoring sites in London, and so limited data is available about this particular pollutant.

Working with the Dustbox and a platform for analysing and viewing citizen data, the Citizen Sense research group set up a monitoring network in collaboration with communities and residents in Southeast London. The network ran for nearly 10 months from December 2016 until September 2017 and collected both sporadic and consistent data at up to 30 monitoring locations. In the course of setting up our particulate matter Dustbox sensors, we worked with participants to consider multiple ways of interpreting and mobilizing citizen data. We held data workshops to work through how to analyse ongoing readings, and to discuss people's observations of pollution events. As the citizen data assembled into a distinct body of evidence, it became clear that these particular practices for monitoring pollution were not simply replicating-or even challenging-official monitoring stations. Instead, they were generating distinct ways of tuning into, engaging, and recasting urban environments as lived, bodily, spatial, collective and planetary encounters with air pollution (Gabrys, 2019a).

After nearly 10 months of monitoring, we had gathered multiple accounts and proposals from people about their attempts to observe and improve the urban realm, along with the citizen air quality data that they generated. We brought these materials together into a series of seven "Deptford Data Stories" that corresponded to monitoring locations and documented findings from the citizen data in those areas (Citizen Sense, 2017; Fig. 1). We developed the data stories as a collaborative method that could bring together numerical sensor data, citizen observations, mapping, council planning activities, and proposals for 


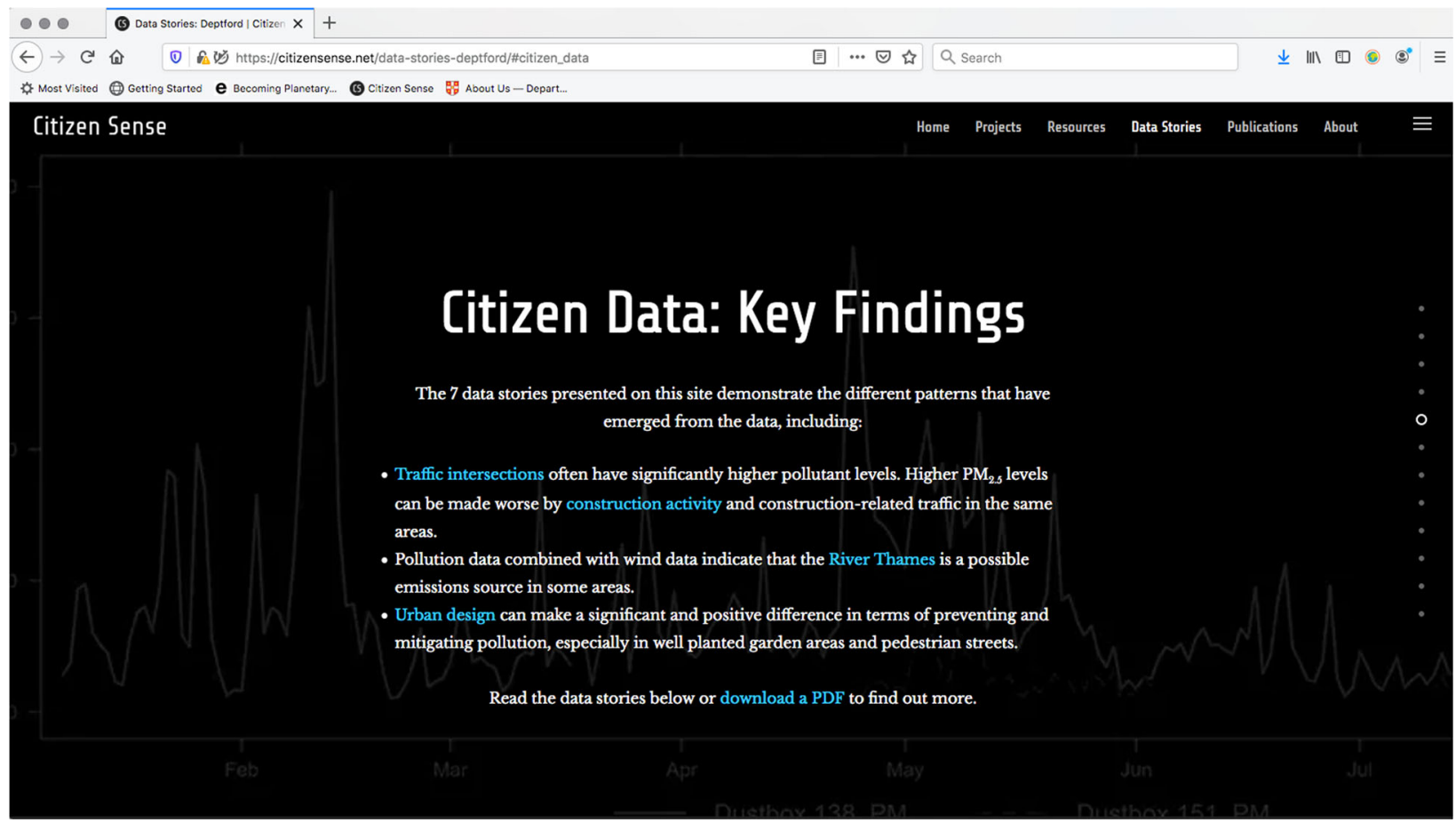

Fig. 1 Deptford Data Stories website, main findings (Citizen Sense, 2017).

addressing pollution levels. These were ways of crafting stories as open processes, rather than closed accounts, which could spark and facilitate public debate (cf. Petryna, 2013, p. xxvi). Prior to launching the data stories, we held a data workshop with community groups and participants to talk through the findings, and to co-author a series of actions for addressing the findings. Participants were keen not to have the findings simply reveal whether pollution levels were harmful, but rather to use the spatial, temporal, and situational aspects of the data to support projects and proposals for improving the urban realm.

These co-authored actions were then included as part of the Deptford Data Stories, which circulated to wider publics, the press, policymakers, and regulators, as well as environmental scientists. The action points sought in various ways to realize healthier environments and collective relations. However, the action points were inconsistently received and acted upon as attempts to shape and influence the urban environment. The politics of health, in this sense, emerged through struggles over what makes for a healthy environment, as well as how to intervene in environments to make them more liveable. Health was approached not necessarily or only as a concatenation of individual bodies, but rather as something that is made and sustained within environments. In this way, health involved developing environmental interventions in order to transform bodies, relations, politics, sociality, and lived material conditions. For the remainder of this article, I will discuss how three of these action areas worked toward health as a collective and planetary project, often with uneven results. It is these differential and complex aspects of influencing and transforming health as a collective project that I highlight, as well as the extent to which the inability to influence or transform environments reinforces the inequalities and injustices that planetary health would counteract.

Deptford Park: experiments in urban movement. Deptford Park is one monitoring location that, along with other monitoring locations such as New Cross Gate and Deptford Bridge, had high levels of pollution evident near roadways due to traffic. Located within the Ward of Evelyn, Deptford Park has a relatively poor transport infrastructure, with lack of connectivity to train, tube and bus links. Evelyn is among one of the most deprived wards in the UK, with a child poverty rate of 49 percent. ${ }^{4}$ At the same time, people typically do not own cars and are reliant on public transport for travel. It has been well documented by residents in the area that it is very difficult to travel between their homes and the nearest schools, shops and facilities in the area. The problem of transport is then at least double-fold, in that people are not able to easily travel with public transport and so they will have to resort to more expensive private vehicles for travel, while at the same time a large proportion of traffic in the area consists of private vehicles passing through from other areas and even taking advantage of freely available parking spaces that are not used by local residents.

During the course of monitoring at several locations in the Deptford Park area (Fig. 2), one community group, Deptford Folk, began a campaign to investigate the overall problem of mobility in the area. They worked with planners from the Lewisham Council to set up transportation pilots and experiments that temporarily shut down busy roads and implemented alternative road layouts so as to encourage walkability and cycleability. They developed cycle repair workshops, investigated how to make more throughways underneath rail arches that divided the area, and used these investigations to develop a collaboration with a sustainable transport charity, Sustrans. Together with Sustrans, Deptford Folk submitted a bid to the Transport for London (TFL) "Liveable Neighbourhoods" funding scheme to more extensively implement improvements to transport in the area. Deptford Folk used some of the preliminary findings from their air pollution citizen data to document how busy roads in the area had elevated pollution levels, and that this could pose a problem for nearby schools and public facilities.

While the results of their bid to TFL were pending, Deptford Folk then addressed the many problem areas related to transport that they had identified, while joining up these observations with the pollution data that they and their neighbours were collecting. When we held our preliminary data stories launch workshop, 


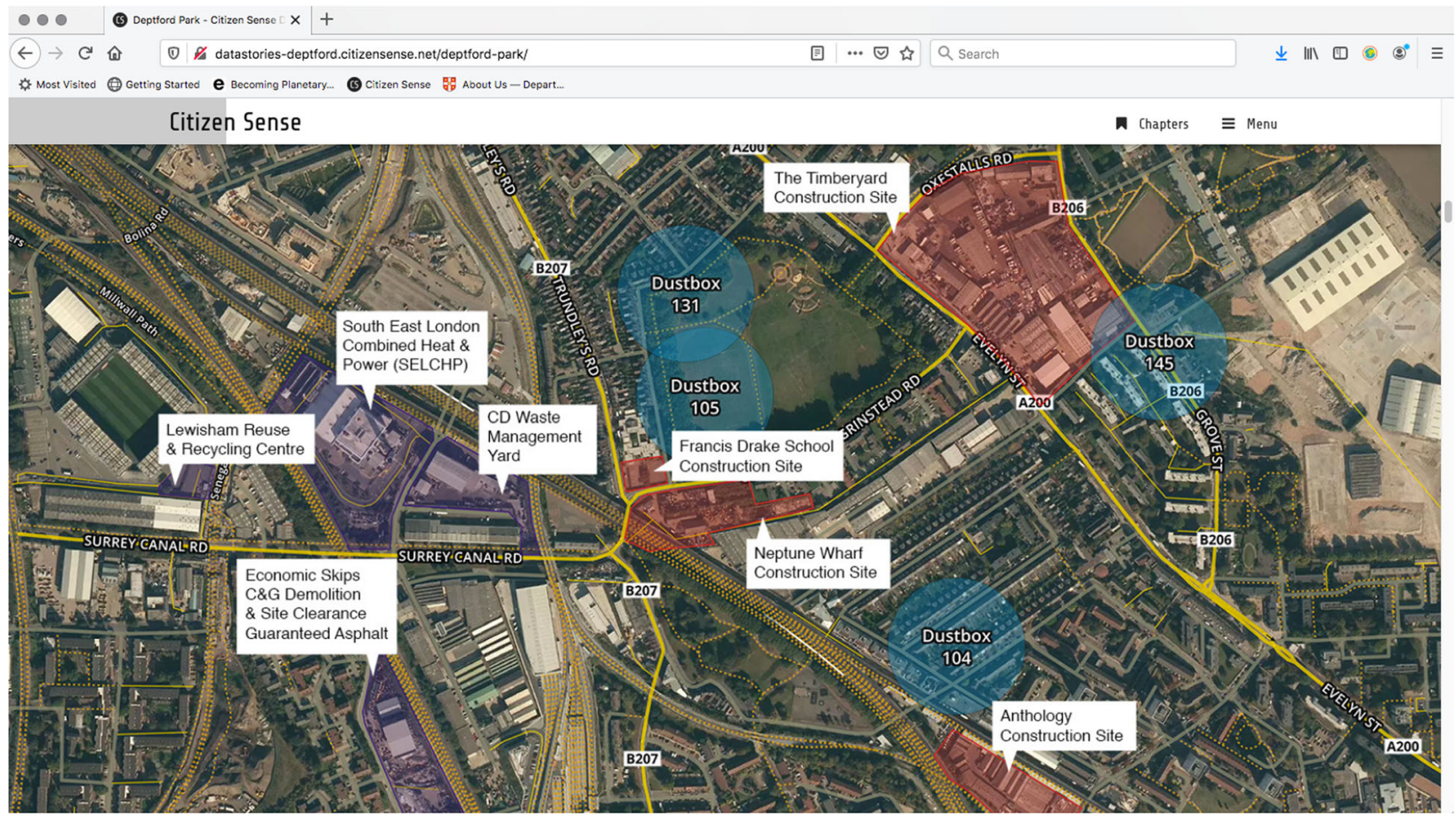

Fig. 2 Mapping Deptford Park, Deptford Data Stories (Citizen Sense, 2017).

they worked along with several other community groups and participants to contribute action points to the data stories that included building on Lewisham plans to develop a coherent traffic management plan for the area, especially addressing pedestrian, cycle, and public transport routes. Transport actions sought to address the impact of increasing development and numbers of residents in the area to ensure that a parallel increase in cars would not occur. They especially underscored the need to encourage and support the transportation pilots underway in the area through the partnership between Deptford Folk and Sustrans, and that practices from these transportation pilots could be extended to other areas so as to encourage the pedestrianization of roadways especially near schools and parks. ${ }^{5}$

These action points for sustainable transport sought to build on existing partnerships, initiatives, observations, monitoring, and urban experiments in order to expand and improve possibilities both for shaping urban environments and for developing more accountable and participatory methods. Deptford Folk and Sustrans were ultimately successful in receiving funding from TFL for $£ 2.9$ million to undertake a Liveable Neighbourhoods sustainable transport project beginning in 2017. ${ }^{\circ}$ While local residents attending the Evelyn Assembly meetings continue to point out that their arguments for better transport go unheard and unheeded by Lewisham Council (although this has shifted somewhat since the Covid-19 lockdown), community groups are at the same time attempting to implement transport projects that directly shape and transform the urban realm, with the intention of having successful pilots influence other areas in the Borough. practices for planetary health benefited from collaborations, networks, and funding to spark urban interventions into action. At the same time, community groups and residents continue to work to embed these interventions as a more pervasive approach to the urban realm, where development projects and entrenched transport patterns, along with deep-seated inequality make these practices at times difficult to realize in a more extensive register across urban communities throughout this area. Here, the planetary becomes evident through transformed affiliations across communities, environments and health, in ways that are more operational rather than all-encompassing, where planetary health materializes through modes of concern and action for lived but differential environments, rather than as a total view.

Old Tidemill Wildlife Garden: community struggles for green infrastructure. Old Tidemill Wildlife Garden ${ }^{7}$ is a second monitoring location that, along with other sites in New Cross Gate, demonstrated the possible benefits of green space in mitigating pollution from particulate matter. Residents living nearby the garden, along with community groups such as Deptford Neighbourhood Action and Voice for Deptford, were engaged in an ongoing battle with Lewisham Council to establish the benefits of the green space to the community, as the site was slated for a new housing development that was undergoing planning review at the time when the air-quality monitoring began. Local residents and community groups teamed up with an architecture and urban design group to propose alternative development plans for the site that could preserve green space and social housing, while providing space to develop new housing. They made the case that the site was a local preserve for biodiversity (hence referring to the site as a "wildlife" garden), and a much-needed haven within an area that has relatively few green spaces. As part of these activities, residents and communities groups ran wildlife workshops in the garden, they integrated proposals for the green space into a neighbourhood plan, and they undertook multiple campaign and communication activities, from fundraising events in the garden to blogging and communicating events to the press.

Participants chose to locate Dustbox sensors around the Old Tidemill Wildlife Garden in order to research whether the garden might have a mitigating effect on air quality. In this sense, monitoring was not a stand-alone activity, and data collection did not merely fill gaps in the record of knowledge. Instead, the collection of data and formation of evidence became part of ongoing practices and occurred in order to support and mobilize this campaign to save the wildlife garden. In our pre-launch workshop where we analysed findings from the citizen data, we found that lower air pollution levels were evident near the garden, while higher air pollution levels could be found on nearby busy 
roads, which in some cases had significantly higher levels of pollution. On this basis, we worked with participants to draw out these findings from the data in order to propose a series of actions that could help to further establish the positive benefits of green spaces for mitigating air pollution, and to generate strategies for preserving and protecting this space.

The actions that we co-wrote outlined strategies for promoting and protecting green infrastructure, including compiling an audit of green spaces in the area to identify how to improve green infrastructure opportunities for mitigating air pollution, while improving walkability and cycleability in the area. Such strategies further proposed developing a tree planting plan; enhancing airquality-mitigating vegetating in key sites, such as schools, hospitals and playgrounds; creating community resources for air quality planting, including identifying ideal species and optimal planting arrangements; and hosting events in green spaces in order to raise awareness about the role of urban design in improving air quality. These actions were developed as concrete interventions that drew together ongoing projects and campaigns, built on evidence from citizen air pollution data, and worked toward improving the health of urban environments.

Several months after the completion of the Old Tidemill Data Story, participants also sought to use their proposals, data and materials in planning meetings to argue for the preservation of the Old Tidemill Wildlife Garden green space, and for the adoption of alternative plans that might respect the need for green space in this area. Residents and community members attended multiple planning meetings, and engaged in a protracted and at times heated struggles to protect the garden. However, Lewisham Council ultimately approved the application to develop housing on the site, arguing that there was a shortfall of 10,000 homes in the area. While citizen data collected through this study demonstrated that green spaces had a significant mitigating effect in other local areas including in New Cross Gate and Deptford Park, this evidence did not significantly influence councillors or planners to pursue alternative options for the site.

At the same time, numerous other developments were underway in the area surrounding Old Tidemill Wildlife Garden, including the Thames Tideway Super Sewer that involved felling numerous plane trees, and the construction of a new housing developing adjacent Deptford Church Street that involved felling multiple additional trees. The latter development became the target of intense opposition, with residents communicating to the media the news that the housing development would advise residents not to open their windows during peak traffic times due to air pollution concerns. ${ }^{8}$ Despite having evidence to support their claims about high air pollution levels in the area and the benefits of green infrastructure, as well as being involved in attending planning meetings, campaigning, and proposing alternative strategies for the site, residents and community groups found they were unable to shape their environment in ways that might contribute to a collective sense of improved health in the area. The inability to contribute to a collective project of health through environmental actions became a source of considerable stress for people who felt their communities were subject to widespread development and gentrification, and were changing beyond recognition.

Citizen Sense participants involved in monitoring air quality were often keenly aware of the inequalities that were present in who was able to decide what a healthy environment looks like, and who was able to influence proposals for and implementations of healthier environments. Here, the actions that civic groups would attempt to mobilize were met with disruption and discord when in exchange with local and urban government, private companies and national infrastructure projects. While citizen monitoring can give rise to disagreements over observations and data, attempts to propose actions that might catalyse more environmental, democratic and planetary approaches to health also become sites of struggle. These struggles are, moreover, emblematic of attempts to redefine, reconstitute and transform health and the planetary toward more situated and lived engagements, which are as often refused by actors working within other "layers" of governance that are presumed to be complementary within the usual framing of planetary health. When the planetary is approached as a fixed matter of scale, it can then also presuppose the most legitimate modes of governance for managing the planetary. Yet the planetary must always materialize through distinct sites and practices, which require attending to how citizen engagement does not merely augment a whole-earth view with additional data, but brings the planetary down to earth into multiple practices that are generating situated approaches to planetary health in the making.

Pepys: detecting river pollution through citizen monitoring. The Pepys area ${ }^{9}$ is a third monitoring location where residents and members of community groups undertook air quality monitoring initially to understand the impact of increased construction in the area. Pepys is characterized by multiple housing estates situated within a relatively green area, which includes community gardens and open spaces. Because this location is located near the River Thames and is somewhat removed from major thoroughfares, we did not expect to detect significantly elevated pollution levels, with the possible exception of nearby construction activity. In addition to several active construction sites on the perimeter of the area, the South East London Combined Heat and Power (SELCHP) incinerator was visible from the two central monitoring locations in this area, so participants were interested to see whether they would be able to register these possible pollution sources.

In the course of monitoring, we began to notice higher pollution levels at distinct times of day and week, which could not clearly be attributed to any particular source. After several workshops and meetings with residents and community members where we worked through the citizen data using our air quality data-analysis toolkit, Airsift, we established that pollution was highest when winds were from the east and northeast. This pattern pointed toward two possible sources-the nearby Convoys Wharf site, a 40-acre brownfield site that was slated for development but was currently sitting dormant as a relatively barren site with scattered historic naval buildings; or the River Thames. After using our data analysis toolkit to rule out the possibility of wind-blown dust from Convoys Wharf as the source of particulate matter, we were able to establish that pollution was very likely due to river traffic powered by marine fuel and diesel oil, which are particularly damaging to air quality.

Not only had the citizen-sensing monitoring network produced new findings about air pollution that regulatory and expert networks had not established (due in part to the particular siting of regulatory monitoring infrastructures), but also it demonstrated the importance of expanded evidentiary practices as a way to document and propose alternative approaches to urban environments. Data here was not merely additional knowledge; instead, it shifted the focus and understanding of possible pollution sources in the area. On the basis of these findings, we worked with participants to co-author proposals for action. These included proposals to upgrade to cleaner ship fuel especially for river vessels to be used for the transport of debris and construction materials for Convoys Wharf. Additional proposals included establishing and expanding citizen-led air quality monitoring networks through resources for community organizations, schools, and residents in order to detect pollution where 
monitoring infrastructure might not be located, and to assess the effectiveness of ongoing preventative and mitigating measures through citizen monitoring.

These proposals for community monitoring networks did not seek to replace or simply augment official monitoring, but rather sought to establish how citizen sensing could provide different, and at times challenging, data and observations that could contribute to the collective project of identifying and improving urban environments. These proposals have not yet been taken up in a systematic way, and attention to improving pollution levels on the river has been uneven due to competing levels of governance across the Greater London Authority and the Port of London Authority. While citizen observations and data were able to establish that pollution was occurring, structures of environmental governance did not so easily or readily allow for this problem to be addressed. Just as the ability to make claims about air pollution through evidentiary practices does not entirely or typically adhere to an "equality of perception", so too does the ability to work within and shape urban environments not unfold through equal access or ability to influence these spaces. The challenges of planetary health-to rework conceptions, data and governance-then prove not to unfold so seamlessly. Indeed, the process of developing alternative approaches to air pollution as a key concern of planetary health demonstrates how a plurality of engagements and epistemes generates struggle over how best to document, sense, and act upon this problem.

\section{Discussion and conclusion: planetary propositions for urban air}

In these multiple citizen-led actions, health exceeded the contours of individual bodies, and became an environmental problem a planetary project that generated new sites of collective responsibility. Health became entangled with and configured through problems of urban democratic life, since practices for addressing the problem of air pollution necessarily collided with problems of urban development, entrenched local and national politics, unsustainable transport policies, and unresponsive industry spokespeople and regulators. Health does not settle here into a set of lifestyle changes or behavioural guidance, nor is it evident as a total overview of systems in which to intervene. Instead, health involves a more political and democratic set of encounters with the lived environments that are generating and exacerbating polluting conditions that span from London to innumerable cities around the world. Planetary health here comes into view through practices whereby distinct environments and processes are made and sustained, with material consequences for the multiple entities that live in these conditions.

Citizen practices for monitoring the air are neither a straightforward project of collecting data, nor do they necessarily lead to effective actions for addressing pollution. Rather than suggest that sensors activate an awareness of pollution, the findings from this research instead indicate that people were relatively informed about pollution levels. Within the monitoring locations described here, multiple community projects were already ongoing, new proposals were being made through additional monitoring, and air quality evidence began to augment and inform initiatives that people were attempting to implement and support. In this context, air-quality monitoring became not simply a practice of gathering data for data's sake, but rather involved interactions across sensors, monitoring networks, pollution hotspots, construction sites, development projects, planning and assembly meetings, and proposals for and against local council initiatives. The data stories that the Citizen Sense research group co-authored along with participants became a way to narrate citizen data while putting forward proposals to improve the health of the urban area. Democratized environmental evidence was thus entangled with attempts to democratize environmental actions.

Such a processual and differential approach to planetary health further demonstrates the inequalities that are sedimented into urban spaces and processes, and the difficulties that arise when attempting to transform environments toward healthier conditions. Those who are not authorized to contribute to the formation of urban spaces, or whose voices have varying levels of audibility and legibility, find that their struggles to improve planetary health can fail to have effect. These collective projects to monitor and develop alterations to the urban realm thus demonstrate the need to consider the situated inequalities and relations that contribute to distinct formations of planetary health. Planetary health signals more than the connection-or assumed prior disconnection-between "human" and "natural" systems. The planetary in planetary health surfaces here less as a universal condition (Haines et al., 2018; Horton et al., 2014; Whitmee et al., 2015) and more as a process of making and challenging relations in order to realize more just planetary inhabitations (Gabrys, 2018). In its joining up of health across environments, bodies, politics, entities and social relations, planetary health demonstrates the uneven conditions in which health forms. This approach involves more than recasting environmental health or global health as planetary health, since the planetary necessarily materializes as a proposition. Such a proposition asks how it might be possible to recognize the differential conditions of air pollution, while transforming our multiple environmental inhabitations through attention to justice and collective responsibility across human and more-than-human relations (cf. Greenhough, 2010).

In these analyses of pollution-oriented action, I have drawn on literature from science and technology studies, environmental justice and postcolonial theory, and planetary health literature to depart from an approach to health that might begin with an individual body and its connection to environmental pollution through bodily harm, or from a predetermined notion of the "planetary scale," and instead have considered how planetary health materializes as an array of environmental and social relations that become active sites for intervention. As necessary as a move to planetary health might be, these actions further demonstrate how the usual contours of the "planetary" are then remade through diverse formations of planetary subjects, thought and practice (cf. Spivak, 1999). Environmental actions can articulate expanded approaches to health both as more-thanindividual affairs, and as planetary processes that differently configure subjects and relations.

Such actions require a greater attention to the power struggles that materialize through attempts to configure and transform health, as well as from attempts to intervene within and remake the lived conditions of environments. This discussion proposes that an expanded attention to the constitution of planetary health (both in terms of the planetary and health) could give rise to more equitable and engaged practices for being and becoming healthy as a collective and yet also differential project that has the potential to transform environments. Planetary health thus sparks a re-engagement with the "body politic" in the full sense of the term, where the conditions of "social health" and social justice are attended to (Nelson, 2011, pp. 11-12), along with the heterogeneous entities involved in composing worlds. By querying the "planetary" in planetary health, it might be possible to open up toward more democratic and expansive practices for constituting health through environmental and collective projects. Within such a project, citizen-sensing practices can serve as propositions and provocations for how to encounter and compose health as a collective, environmental-and planetary-project that seeks to ensure collective flourishing. 


\section{Data availability}

Data discussed in this article is available at the Citizen Sense website, https://citizensense.net. The Deptford Data Stories are available at https://citizensense.net/data-stories-deptford/. The citizen air pollution data that contributed to the Deptford Data Stories is available for analysis and download at http:// citizensense.net/kits/airsift-dustbox/. Dustbox ID-numbers in the Airsift toolkit correspond to the Dustbox ID-numbers in the Deptford Data Stories. The Airsift code is available on the Citizen Sense Github repository at https://github.com/citizensense/airsift. Airsift builds on the openair open-source software developed by David Carslaw, which is available at http://davidcarslaw.github.io/ openair/.

Received: 30 December 2019; Accepted: 30 June 2020; Published online: 15 July 2020

\section{Notes}

1 The estimates for deaths related to indoor and outdoor air pollution vary, but a study by Lelieveld et al. (2019) indicates that the total from both forms of air pollution could be as high as 8.8 million worldwide. An earlier study cited by the Lancet puts the total figure for premature deaths due to all forms of environmental pollution at 9 million worldwide, with 92 percent of this total occurring in low-income to middle-income countries. The total number of premature deaths due to air pollution in this same study is estimated to be 6.5 million worldwide (Das and Horton, 2017). However, the WHO now indicates that premature deaths due to air pollution are estimated to be 7 million, with 4.2 million deaths attributable to ambient air pollution. See World Health Organization, "Air Pollution", https://www.who.int/health-topics/air-pollution.

2 For instance, at the time of this writing the "Plant a Sensor" project is launching, with the objective to collection "one billion data points" for analysing air pollution in relation to buildings. However, it is unclear what these data points would consist of, how they would be analysed, and what their significance would be for affected communities. See https://www.worldgbc.org/plant-a-sensor.

3 In coining this phrase, Nelson draws on Latour's well-known statement, "Science...is politics by other means". See Latour (1988), 229.

4 End Child Poverty, Local data for London, http://www.endchildpoverty.org.uk/ poverty-in-your-area-2019. Accessed 6 Dec 2019. The rate of 49 percent is inclusive of housing costs.

5 The Deptford Park data story is available at https://datastories-deptford.citizensense. net/deptford-park. Accessed 6 Dec 2019.

6 Deptford Parks Liveable Neighbourhood, https://www.deptfordfolk.org/dpln. Accessed 6 Dec 2019.

7 The Old Tidemill Wildlife Garden data story is available at https://datastoriesdeptford.citizensense.net/old-tidemill. Accessed 6 Dec 2019.

8 This housing development was extensively covered in the media. For example, see Noor P (2019) Housing approved despite pollution warning to keep windows shut. The Guardian (12 April), https://www.theguardian.com/environment/2019/apr/12/ london-housing-approved-in-area-with-illegal-pollution-levels-lewisham. Accessed 6 Dec 2019.

9 The Pepys data story is available at https://datastories-deptford.citizensense.net/pepys. Accessed 6 Dec 2019.

\section{References}

Beck U (1993) Risk society: towards a new modernity. Sage Publications, London Benjamin R (2013) People's science: bodies and rights on the stem cell frontier. Stanford University Press

Bickerstaff K, Walker G (2003) The place(s) of matter: matter out of place-public understandings of air pollution. Prog Hum Geogr 27(1):45-67

Bullard R (1990) Dumping in Dixie: race, class, and environmental quality. Westview Press, Boulder

Chatzidiakou L, Krause A, Popoola OAM, Di Antonio A, Kellaway M, Han Y, Squires FA, Wang T, Zhang H, Wang Q, Fan Y, Chen S, Hu M, Quint JK, Barratt B, Kelly FJ, Zhu T, Jones RL (2019) Characterising low-cost sensors in highly portable platforms to quantify personal exposure in diverse environments. Atmos Meas Tech 12:4643-4657

Chilvers J, Kearnes M (eds) (2016) Remaking participation: science, environment and emergent publics. Routledge, London

Citizen Sense (2017) Deptford data stories. https://citizensense.net/data-storiesdeptford. Accessed 6 Dec 2019

Corburn J (2005) Street science: community knowledge and environmental health justice. MIT Press, Cambridge
Das P, Horton R (2017) Pollution, health, and the planet: time for decisive action. The Lancet 391:407-408

DeLoughrey E (2014) Satellite planetarity and the ends of the earth. Public Cult 26 (2):257-280

Dockery DW, Pope CA, Xu X, Spengler JD, Ware JH, Fay ME, Ferris Jr BG, Speizer FE (1993) An association between air pollution and mortality in six U.S. cities. New Engl J Med 329(24):1753-1759

Ekins P, Gupta J, Boileau P (eds) (2019) Global Environment Outlook GEO-6: healthy planet, healthy people. Cambridge University Press, Cambridge

English PB, Richardson MJ, Garzón-Galvis C (2018) From crowdsourcing to extreme citizen science: participatory research for environmental health. Annu Rev Public Health 39:335-350

Epstein S (1995) The construction of lay expertise: AIDS activism and the forging of credibility in the reform of clinical trials. Sci Technol Hum Values 20 (4):408-437

European Commission (2008) Directive 2008/50/EC of the European Parliament and of the Council of 21 May 2008 on Ambient Air Quality and Cleaner Air for Europe. Off J Eur Union (6 November), L 152/1

Felt U, Fochler M (2010) Machineries for making publics: inscribing and describing publics in public engagement. Minerva 48(3):219-238

Fortun K, Fortun M, Bigras E, Saheb T, Costelloe-Kuehn B, Crowder J, Price D, Kenner A (2014) Experimental ethnography online: the asthma files. Cult Stud 28(4):632-642

Gabrys J (2017) Citizen sensing, air pollution and fracking: from 'caring about your air' to speculative practices of evidencing harm. Sociol Rev 65(2):172-192

Gabrys J (2018) Becoming planetary. E-flux Architecture (2 October), https://www. e-flux.com/architecture/accumulation/217051/becoming-planetary. Accessed 6 Dec 2019

Gabrys J (2019a) Data citizens: how to reinvent rights. In: Bigo D, Isin E, Ruppert E (eds) Data politics: worlds, subjects, rights. Routledge, London

Gabrys J (2019b) How to do things with sensors. University of Minnesota Press, Minneapolis

Garnett E, Green J, Chalabi Z, Wilkinson P (2019) Materialising links between air pollution and health: how societal impact was achieved in an interdisciplinary project. Health 23(2):234-252

Greenhough B (2010) Citizenship, care and companionship: approaching geographies of health and bioscience. Prog Hum Geogr 35(2):153-171

Grigg J (2017) Where do inhaled fossil fuel-derived particles go? Am J Respir Crit Care Med 196(7):804-806

Gupta J, Hurley F, Grobicki A, Keating T, Stoett P, Baker E, Buhl A, Davies J, Ekins $\mathrm{P}$ (2019) Communicating the health of the planet and its links to human health. Lancet: Planet Health 3(5):204-206

Haines A, Hanson C, Ranganathan J (2018) Planetary health watch: integrated monitoring in the Anthropocene epoch. Lancet: Planet Health 2:e141-e143

Hinchliffe S, Jackson M, Wyatt K, Barlow AE, Barreto M, Clare L, Depledge MH, Durie R, Fleming LE, Groom N, Morrissey K, Salisbury L, Thomas F (2018) Healthy publics: enabling cultures and environments for health. Palgrave Commun 4(57):1-20

Holgate ST (2017) Every breath we take: the lifelong impact of air pollution-a call for action. Clin Med 17(1):8-12

Horton R, Beaglehole R, Bonita R, Raeburn J, McKee M, Wall S (2014) From public to planetary health: a manifesto. Lancet 383:847

Horton R, Lo S (2015) Planetary health: a new science for exceptional action. Lancet 386:1921-1922

Houston L, Gabrys J, Pritchard H (2019) Breakdown in the smart city: exploring workarounds with urban sensing practices and technology. Sci Technol Hum Values 44(4):1-28

Kelly AH, Boko Koudakossi HN, Moore SJ (2017) Repellents and new "spaces of concern" in global health. Med Anthropol 36(5):464-478

Landrigan PJ, Fuller R, Acosta NJR, Adeyi O, Arnold R, Basu N, Baldé AB, Bertollini R, Bose-O’Reilly S, Boufford JI, Breysse PN, Chiles T, Mahidol C, CollSeck AM, Cropper ML, Fobil J, Fuster V, Greenstone M, Haines A, Hanrahan D, Hunter D, Khare M, Krupnick A, Lanphear B, Lohani B, Martin K, Mathiasen KV, McTeer MA, Murray CJL, Ndahimananjara JD, Perera F, Potočnik J, Preker AS, Ramesh J, Rockström J, Salinas C, Samson LD, Sandilya K, Sly PD, Smith KR, Steiner A, Stewart RB, Suk WA, van Schayck OCP, Yadama GN, Yumkella K, Zhong M (2018) The Lancet Commission on pollution and health. Lancet 391:462-512

Latour B (1988) The pasteurization of France. Harvard University Press, Cambridge

Lelieveld J, Klingmüller K, Pozzer A, Pöschl U, Fnais M, Daiber A, Münzel T (2019) Cardiovascular disease burden from ambient air pollution in Europe reassessed using novel hazard ratio functions. Eur Heart J 40 (20):1590-1596

Loxham M, Davies DE, Holgate ST (2019) The health effects of fine particulate air pollution: the harder we look, the more we find. BMJ 367(16609):1-12

Michael M (2009) Publics performing publics: of PiGs, PiPs and politics. Public Underst Sci 18(5):617-631 
Nelson A (2011) Body and soul: the Black Panther Party and the fight against medical discrimination. University of Minnesota Press, Minneapolis

Ottinger G (2010) Buckets of resistance: standards and the effectiveness of citizen science. Sci Technol Hum Values 35(2):244-270

Petryna A (2013) Life exposed: biological citizens after Chernobyl. Princeton University Press, Princeton, (first published 2003)

Pritchard H, Gabrys J (2016) From citizen sensing to collective monitoring: working through the perceptive and affective problematics of environmental pollution. GeoHumanities 2(2):354-371

Pulido L (2016) Flint, environmental racism, and racial capitalism. Capital Nat Social 27(3):1-16

Royal College of Physicians (2016) Every breath we take: the lifelong impact of air pollution. Report of a working party. RCP, London. https://www.rcplondon. ac.uk/projects/outputs/every-breath-we-take-lifelong-impactair-pollution. Accessed 6 Dec 2019

Schraufnagel DE, Balmes JR, De Matteis S, Hoffman B, Kim WJ, Perez-Padilla R, Rice M, Sood A, Vanker A, Wuebbles DJ, on behalf of the Forum of International Respiratory Societies Environmental Committee (2019) Health benefits of air pollution reduction. Ann Am Thorac Soc 16(12):1478-1487

Smith LT (1999) Decolonizing methodologies: research and indigenous peoples. Zed Books, London

Spivak GS (1999) Imperatives to re-imagine the planet. Passagen Verlag, Vienna

Sze J (2007) Noxious New York: the racial politics of urban health and environmental justice. MIT Press, Cambridge

Tuck E, Smith M, Guess AM, Benjamin T, Jones BK (2013) Geotheorizing black/ land: contestations and contingent collaborations. Depart Crit Qual Res 3 (1):52-74

Walker G (2012) Environmental justice: concepts, evidence and politics. Routledge, London

Whitmee S, Haines A, Beyrer C, Boltz F, Capon AG, Ferreira de Souza Dias B, Ezeh A, Frumkin H, Gong P, Head P, Horton R, Mace GM, Marten R, Myers SS, Nishtar S, Osofsky SA, Pattanayak SK, Pongsiri MJ, Romanelli C, Soucat A, Vega J, Yach D (2015) Safeguarding human health in the Anthropocene epoch: report of The Rockefeller Foundation-Lancet Commission on planetary health. Lancet 386:1973-2028

World Health Organization (2005) WHO air quality guidelines for particulate matter, ozone, nitrogen dioxide and sulfur dioxide: global update 2005. World Health Organization, Geneva, Switzerland

Yearley S (2011) Citizen engagement with the politics of air quality: lessons for social theory, science studies, and environmental sociology. In: Lidskog R, Sundqvist G (eds) Governing the air: the dynamics of science, policy, and citizen interaction. MIT Press, Cambridge, pp. 253-271

\section{Acknowledgements}

Thanks are due to Helen Pritchard, Lara Houston, Lau Thiam Kok, Benjamin Barratt, Khadija Jabeen, Sarah Garcin, Raphael Faeh, Francesca Perona and Adrian McEwen for contributing to the collaborative research, design, calibration and development of the Citizen Sense research in Southeast London. Thanks are also due to the participants of the urban sensing project, and to the organizations that have hosted workshops and events, including Deptford Folk, Deptford Neighbourhood Action, Peyps Estate, Crossfields Estate, Voice for Deptford, APT Gallery, New Cross Gate Trust, Deptford Lounge Library and New Cross Learning. The research leading to these results has received funding from the European Research Council under the European Union's Seventh Framework Programme (FP/2007-2013)/ERC Grant Agreement no. 313347, "Citizen Sensing and Environmental Practice: Assessing Participatory Engagements with Environments through Sensor Technologies".

\section{Competing interests}

The author declares no competing interests.

\section{Additional information}

Correspondence and requests for materials should be addressed to J.G.

Reprints and permission information is available at http://www.nature.com/reprints

Publisher's note Springer Nature remains neutral with regard to jurisdictional claims in published maps and institutional affiliations.

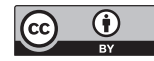

Open Access This article is licensed under a Creative Commons Attribution 4.0 International License, which permits use, sharing, adaptation, distribution and reproduction in any medium or format, as long as you give appropriate credit to the original author(s) and the source, provide a link to the Creative Commons license, and indicate if changes were made. The images or other third party material in this article are included in the article's Creative Commons license, unless indicated otherwise in a credit line to the material. If material is not included in the article's Creative Commons license and your intended use is not permitted by statutory regulation or exceeds the permitted use, you will need to obtain permission directly from the copyright holder. To view a copy of this license, visit http://creativecommons.org/ licenses/by/4.0/.

(C) The Author(s) 2020 